\title{
Interaction between COX-1 and COX-2 increases susceptibility to ischemic stroke in a Chinese population
}

\author{
Lei Zhao ${ }^{\dagger}$, Jinghuan Fang ${ }^{\dagger}$, Muke Zhou, Jie Zhou, Lihua Yu, Ning Chen and Li He* (D)
}

\begin{abstract}
Background: Mutations of cyclooxygenase gene (COX gene) may increase the susceptibility of ischemic stroke. We investigated five variants (rs5788, rs1330344, rs3842788, rs20417, and rs689466) of two COX genes in order to explaining the association between these polymorphisms and we also investigated the association between these variants and ischemic stroke risk to determine whether gene-gene interaction between these genes increases the susceptibility of ischemic stroke or its subtypes.

Methods: A total of 1981 study subjects (1078 cases and 903 control subjects) were recruited. The interaction of multiple factors was investigated using Multifactor Dimensionality Reduction. The additive effect of single nucleotide polymorphisms on ischemic stroke or its subtypes were analyzed by multiple factor logistic regression.

Results: At COX-1(rs1330344), AA genotype carriers had a lower susceptibility of ischemic stroke $(O R=0.657$, $95 \% \mathrm{Cl}=0.437-0.988, P=0.044)$, and A allele carriers had a lower susceptibility of ischemic stroke $(O R=0.812$, $95 \% \mathrm{Cl}=0.657-0.978, P=0.029)$. At COX-1(rs3842788), AA genotype carriers had a higher susceptibility of ischemic stroke $(O R=5.203,95 \% \mathrm{Cl}=1.519-5.159, P=0.016)$. At COX-2 (rs689466), AA genotype carriers had a higher susceptibility of large-artery atherosclerosis $(O R=1.404,95 \% \mathrm{Cl}=1.019-1.934, P=0.038)$. COX-1(rs1330344, rs3842788) and COX-2 rs689466 interacted in SVO, but had no additive effect with ischemic stroke and other subtypes.

Conclusions: At rs1330344, AA genotype may reduce the susceptibility of ischemic stroke. At rs3842788, AA genotype may increase the susceptibility of ischemic stroke. At rs689466, AA genotype may increase the susceptibility of large-artery atherosclerosis (LAA). COX - 1(rs1330344, rs3842788) and COX-2 rs689466 interacted in small vessel occlusion (SVO), but had no additive effect with ischemic stroke and other subtypes.
\end{abstract}

Keywords: Ischemic stroke, COX-1, COX-2, Single nucleotide polymorphism, Gene-gene, Interaction

\section{Background}

Stroke is a common cerebrovascular disease, which is the second cause of disability and mortality worldwide. The most common type of stroke is ischemic stroke, which accounts for approximately $80 \%$ of all stroke cases $[1,2]$. As a complex disease, ischemic stroke was characterized by several etiological factors and likely affected by various genes, environments, lifestyles, and other causes; which could produce complex high-order interactions to this disease [3-6].

\footnotetext{
* Correspondence: heli2003new@126.com

${ }^{\dagger}$ Zhao Lei and Fang Jinghuan contributed equally to this work.

Department of Neurology, West China Hospital of Sichuan University, No.37,

Guoxue Road, Chengdu, Sichuan 610041, People's Republic of China
}

Researchers had found that lipid metabolism, blood coagulation, fibrinolysis system and inflammatory factors played a very important role in the pathogenesis of ischemic stroke [5]. On one hand, the mutation of some gene involved in the inflammatory response can cause the internal environment disturbance which might lead to the occurrence and development process of atherosclerosis. On the other hand, ultimately unstable or ruptured atherosclerotic plaque will cause the occurrence of acute cerebrovascular diseases. Therefore, Atherosclerosis is the main pathophysiological basis of both cardiovascular and cerebrovascular diseases. Atherosclerosis is a kind of multifactorial disease, involving many factors such as gene, environment, metabolic interaction at the

(c) The Author(s). 2019 Open Access This article is distributed under the terms of the Creative Commons Attribution 4.0 International License (http://creativecommons.org/licenses/by/4.0/), which permits unrestricted use, distribution, and reproduction in any medium, provided you give appropriate credit to the original author(s) and the source, provide a link to the Creative Commons license, and indicate if changes were made. The Creative Commons Public Domain Dedication waiver (http://creativecommons.org/publicdomain/zero/1.0/) applies to the data made available in this article, unless otherwise stated. 
same time and also a kind of participation by a variety of inflammatory cytokines and cell proliferation of chronic inflammation [7]. Furthermore, the adhesion, aggregation and release of platelet is another important part of the thrombosis. The platelet adhesive phenomenon (platelet aggregation) is closely related to thrombosis. In recent years, many scholars have found that the metabolic product of arachidonic acid (AA)plays an important role in the formation of atherosclerosis and thrombosis and is closely related with the incidence of ischemic stroke. Meanwhile AA metabolic disorders affects the stability of vascular endothelium, vasomotor function and platelet aggregation, which lead to the occurrence of vessel diseases $[8,9]$.

Genome-wide association studies (GWAS)have verified various ischemic stroke-associated inflammatory factor genes, including cyclooxygenase or prostaglandin oxidase (COX) [10-17]. COX is a bifunctional enzyme with oxidase and catalase activities. It is also a key enzyme in the arachidonic acid metabolism of prostaglandins (PGs) and thromboxane A2 (TXA2). Prostaglandin E2(PGE2) is involved in inflammation, and TXA2 is implicated in platelet aggregation and vasoconstriction [16]. COX gene is closely related to ischemic stroke, elucidating its genetic mechanism has a great significance in exploring the risk prediction of ischemic stroke and developing new targets for drug treatment. There are two forms of COX in the human body currently: COX-1 and COX-2. One is the structural type COX-1, which is stably expressed in normal cells, catalyzes the formation of PGs to maintain normal physiological function, regulates platelet functional activity and coagulation function. And the other is induced type COX-2, which is only highly expressed when the cells affected by various factors to participates in physiological and pathological processes of inflammation or tumor such as oncogenes, cytokines, growth factor, endotoxin, carcinogen, catalyzes prostaglandin E 2 (PGE2) [18]. Based on this physiological role, we assumed that the mutation of $\mathrm{COX}$ gene may be associated with the susceptibility of ischemic stroke. Maree et al. [19] has demonstrated that COX-1 gene mutation can change the platelet aggregation rate and affect thrombus formation, therefore it would cause thrombotic diseases such as ischemic stroke by regulating arachidonic acid (AA) metabolic processes. GWAS and other related studies have revealed that multiple SNPs of a COX-2 gene can influence inflammatory processes in the human body by regulating the expression of its products, such as PGs increasing the formation of plaque [17]. And there was a study showed that COX-2 is an ischemic stroke-susceptible gene in African-American and European populations [20].

However, there are some controversial researches of COX-1 and COX-2. There is no specific locus associated with ischemic stroke, and the results varied from population to population [21-26]. It maybe because it is hard to use the statistical significance of single SNP studies on ischemic stroke to explain the association between SNPs in the same gene. Therefore, it is very important for us to consider the interacting effects of multiple SNPs on ischemic stroke. So we conducted a largesample case-control study to investigate the association of five variants (rs5788, rs1330344, rs3842788, rs20417, and rs689466) of COX-1 and COX-2 genes with ischemic stroke and to investigate the pattern of genetic variation within COX and to explore whether gene-gene interactions between these genes increase the susceptibility of ischemic stroke or its subtypes.

\section{Methods \\ Samples}

Genomic DNA was isolated from morning fasting peripheral venous blood of 1078 cases of patients with diagnosed of ischemic stroke (ischemic stroke group) and 903 cases of non-ischemic stroke subjects (control group) from the Han racial/ethnic groups in Mainland China. All the patients came from the same region of the Han population and were matched in terms by gender and age. Patients' information was obtained from the stroke database of the Neurology Department of West China Hospital.

The inclusion criteria were as follows: 1 ) age $\geq 40$ years old; 2) the diagnose of ischemic stroke was confirmed by brain magnetic resonance imaging according to WHO diagnostic criteria [27]. Exclusion criteria was as follows: 1) hemorrhagic stroke, or recurrent ischemic stroke; 2) other etiologies of ischemic stroke: stroke of other determined etiology (SOD), or stroke of undetermined etiology (SUD); 3) cerebrovascular malformation or brain tumor. In this study, ischemic stroke group were divided into three subtypes: large-artery atherosclerosis (LAA), cardioembolic stroke (CES), and small vessel occlusion (SVO) according to TOAST typing [28]. We selected the patients without stroke history and none cerebral infarction lesions in CT/MRI into control group. The purpose of the study was described in detail, and informed consents were obtained from all the participants. This study was approved by the Ethics Review Committee of West China hospital, Sichuan University.

\section{Demographic data and characteristics of participants}

The following demographic data and relevant characteristics were obtained: hypertension ( $\mathrm{SBP} \geq 140 \mathrm{mmHg} / \mathrm{DBP} \geq 90$ $\mathrm{mmHg}$ ) or medication intake, diabetes (random blood glucose $\geq 7.0 \mathrm{mmol} / \mathrm{L}$ ) or medication intake, coronary heart disease, hyperlipidemia (cholesterol, $\mathrm{TC} \geq 5.62 \mathrm{mmol} / \mathrm{L} /$, or triglyceride, $\mathrm{TG} \geq 1.92 \mathrm{mmol} / \mathrm{L}$ ) or medication intake, smoking ( $\geq 10$ cigarettes per day, smoking age $>1$ years, or duration of smoking cessation $\leq 3$ years), [29] and drinking (> 
$50 \mathrm{ml} / \mathrm{d},>1$ year). Other data were also collected from patients' medical records.

\section{Genotype determination}

Genomic DNA was isolated with an AxyPrepTM blood genomic DNA maxiprep kit (Axygen Biosciences, USA). Five SNPs of $C O X-1$ and $C O X-2$ were retrieved from the NCBI database (http://www.ncbi.nlm.nih.gov/SNP). Five SNPs selected for our study (based on potential functional significance and minor allele frequency of $>0.10$ )COX-1-644C/A (rs5788), COX-1-1676G/A (rs1330344), COX-1-128G/A (rs3842788), COX-2-765G/C (rs20417), and COX-2-1195G/A (rs689466) [30]. Genotyping was performed in a blinded manner by K-Biosciences (Herts, UK) (http://www.kbioscience.co.uk/) using a competitive allele-specific PCR system (KASPar).

\section{Statistical analysis}

Three common genetic models are used in related studies: dominant, recessive, and additive model. In this study, each SNP contained the major allele $A$ and minor allele $B$. $A B+B B$ versus $A A$ was calculated by the dominant model, $B B$ versus $A B+A A$ was determined by the recessive model, and $A B$ versus $A A$ or $B B$ versus $A A$ was examined by the additive model. The three models for each site were statistically analyzed by SPSS 19.0 (SPSS Inc., Chicago, IL, USA). The frequencies of each allele and genotype were calculated by performing $X^{2}$ test and described as mean \pm SD. The Hardy-Weinberg equilibrium of the five polymorphic distributions of the patients and controls was evaluated through a chi-square goodness-of-fit test. The correlation of the SNPs and their cumulative effects on ischemic stroke were examined through multiple factor logistic regression after adjusted related risk factors, such as gender, age, smoking, and hypertension. The interaction of multiple factors was investigated using MDR version 3.0.2 (http://sourceforge.net/projects/mdr/). Odds ratios were calculated with $95 \%$ confidence intervals. $P<0.05$ was considered statistically significant.

\section{Results}

\section{Study population and baseline characteristics}

There were in total 1981 subjects, including 1078 cases of ischemic stroke patients and 903 cases of control group. The clinical characteristics of the patients and controls were listed in Table 1 . The proportion was higher of hypertension, diabetes, hyperlipidemia, and coronary heart disease, smoking in patient group, and also higher fibrinogen level, lower high-density lipoprotein cholesterol (HDL-C) level and lower blood platelet (PLT) level. There were significant differences of the proportion of men in our study between the case group and the control group. LDL-C level between two groups had no significant difference. These risk factors such as sex, hypertension, diabetes, smoking, alcohol consumption, triglyceride level, platelet level and fibrinogen level were associated with the three subtypes- LAA, CES and SVO groups of ischemic stroke, and the distribution of the three groups was also statistical significantly different.

\section{Genotype and allele frequency distributions of SNPs in ischemic stroke and controls(Table 2)}

At COX-1 (rs5788) andCOX-2 (rs20417), no significant differences were observed in genotype and allele frequencies between the ischemic stroke group including the three subtypes (LAA, CES, SVO) and the control group, even after we using multivariate analysis by adjusting for age, gender and related risk factors.

At COX-1(rs1330344), compared to the GG genotype, the AA genotype carriers had a lower susceptibility of ischemic stroke, and this difference remained significant in multivariate analysis by adjusting for age, gender and traditional risk factors $(O R=0.657,95 \% C I=0.437-$ $0.988, P=0.044)$. And the AA genotype carriers also had a lower susceptibility of CES or SVO (OR $=0.506,95 \%$ $C I=0.262-0.978, P=0.043 ; O R=0.616,95 \% C I=0.382$ 0.995, $P=0.048$ ). Meanwhile, compared to the $\mathrm{G}$ allele, the A allele carriers had a lower susceptibility of ischemic stroke, and this difference remained significant in multivariate analysis by adjusting for age, gender and traditional risk factors $(O R=0.812,95 \% C I=0.675$ 0.978, $P=0.029$ ). And the A allele carriers also had a lower susceptibility of LAA or CES (OR $=0.778,95 \%$ $C I=0.618-0.981, P=0.034 ; O R=0.702,95 \% C I=0.518$ $0.951, P=0.023)$.

At COX-1(rs3842788), compared to the $\mathrm{G}$ allele carriers genotype $(\mathrm{GG}+\mathrm{GA})$, the AA genotype carriers had a higher susceptibility of ischemic stroke, this difference remained significant in multivariate analysis by adjusting for age, gender and traditional risk factors $(O R=5.203$, 95\% $C I=1.519-5.159, P=0.016$ ). And the AA genotype carriers also had a higher susceptibility of CES or SVO $(O R=9.821, \quad 95 \% \quad C I=2.754-12.832, \quad P=0.041 ; \quad O R=$ 4.603, 95\% $C I=1.220-5.201, P=0.025)$.

At COX-2(rs689466), compared to the $\mathrm{G}$ allele carriers genotype $(G G+G A)$, the AA genotype carriers had a higher risk of LAA, this difference remained significant in multivariate analysis by adjusting for age, gender and traditional risk factors $(O R=1.404,95 \% C I=1.019$ 1.934, $P=0.038$ ).

\section{Genotype and allele frequency distributions of SNPs in hypertension/diabetes/smoking and their controls(Table 3)}

We respectively divided all participants into high risk factor group (hypertension/diabetes/smoking groups) and control group. 
Table 1 Baseline Characteristics for INVEST-GENES Participants

\begin{tabular}{|c|c|c|c|c|}
\hline Characteristic & Control group $(n=903)$ & IS group $(n=1078)$ & $P$ value & \\
\hline Age(years) & $57.0 \pm 14.9$ & $64.4 \pm 12.3$ & 0.486 & \\
\hline Sex $($ male\%) & $474(52.5)$ & $677(62.8)$ & $<10^{-3}$ & \\
\hline Hypertension (\%) & $154(17.1)$ & $729(67.6)$ & $<10^{-3}$ & \\
\hline Diabetes (\%) & $59(6.5)$ & $361(33.5)$ & $<10^{-3}$ & \\
\hline Hyperlipidemia (\%) & $90(10.0)$ & $177(16.4)$ & $<10^{-3}$ & \\
\hline Coronary heart disease (\%) & $10(1.1)$ & $115(10.7)$ & $<10^{-3}$ & \\
\hline Smoking (\%) & $244(27.0)$ & $369(34.2)$ & 0.001 & \\
\hline Alcohol consumption(\%) & 175(19.6) & 235(21.9) & 0.214 & \\
\hline $\mathrm{TG}(\mathrm{mmol} / \mathrm{L})$ & $1.50 \pm 1.13$ & $2.27 \pm 24.2$ & 0.342 & \\
\hline $\mathrm{TC}(\mathrm{mmol} / \mathrm{L})$ & $4.36 \pm 1.03$ & $4.27 \pm 2.73$ & 0.311 & \\
\hline $\mathrm{HDL}-\mathrm{C}(\mathrm{mmol} / \mathrm{L})$ & $1.36 \pm 0.43$ & $1.25 \pm 0.50$ & $<10^{-3}$ & \\
\hline $\mathrm{LDL}-\mathrm{C}(\mathrm{mmol} / \mathrm{L})$ & $2.73 \pm 7.05$ & $2.47 \pm 0.96$ & 0.230 & \\
\hline Fibrinogen levels (mmol/L) & $2.20 \pm 1.59$ & $3.16 \pm 1.00$ & $<10^{-3}$ & \\
\hline $\operatorname{Plt}(10 \wedge 9 / L)$ & $178.5 \pm 72.1$ & $169.0 \pm 66.70$ & 0.021 & \\
\hline Characteristic & LAA group $(n=405)$ & CES group $(n=136)$ & SVO group $(n=537)$ & $P$ value \\
\hline Age(years) & $63.2 \pm 12.6$ & $64.5 \pm 12.9$ & $64.9 \pm 11.9$ & 0.079 \\
\hline Sex(male\%) & $274(67.7)$ & $62(45.6)$ & $341(63.5)$ & $<10^{-3}$ \\
\hline Hypertension (\%) & $268(66.2)$ & $65(47.8)$ & $396(67.6)$ & $<10^{-3}$ \\
\hline Diabetes (\%) & $132(32.6)$ & 24(17.6) & $205(38.2)$ & $<10^{-3}$ \\
\hline Hyperlipidemia (\%) & $68(16.8)$ & $13(9.6)$ & $96(17.9)$ & 0.063 \\
\hline Coronary heart disease (\%) & $45(11.1)$ & 18(13.2) & $52(9.7)$ & 0.457 \\
\hline Smoking (\%) & $162(40.0)$ & $25(18.4)$ & 182(33.9) & $<10^{-3}$ \\
\hline Alcohol consumption(\%) & $102(25.2)$ & $17(12.6)$ & $116(21.7)$ & 0.009 \\
\hline $\mathrm{TG}(\mathrm{mmol} / \mathrm{L})$ & $1.65 \pm 1.22$ & $1.26 \pm 0.66$ & $2.52 \pm 27.79$ & 0.042 \\
\hline $\mathrm{TC}(\mathrm{mmol} / \mathrm{L})$ & $4.51 \pm 4.88$ & $4.00 \pm 1.58$ & $4.21 \pm 1.15$ & 0.367 \\
\hline $\mathrm{HDL}-\mathrm{C}(\mathrm{mmol} / \mathrm{L})$ & $1.24 \pm 0.68$ & $1.30 \pm 0.43$ & $1.24 \pm 0.40$ & 0.926 \\
\hline $\mathrm{LDL}-\mathrm{C}(\mathrm{mmol} / \mathrm{L})$ & $2.44 \pm 0.94$ & $2.64 \pm 3.87$ & $2.49 \pm 0.99$ & 0.084 \\
\hline Fibrinogen levels (mmol/L) & $3.22 \pm 0.97$ & $2.98 \pm 1.04$ & $3.16 \pm 1.00$ & 0.012 \\
\hline $\operatorname{Plt}(10 \wedge 9 / L)$ & $171.2 \pm 63.5$ & $151.5 \pm 61.0$ & $171.0 \pm 67.2$ & 0.003 \\
\hline
\end{tabular}

count data:mean \pm SD, measurement data:(\%)

$P<0.05$ in bold

As for hypertension group, at all the five SNPs, no significant differences were observed in genotype and allele frequencies between the hypertension group and control group. After we using multivariate analysis by adjusting for age, gender and related risk factors, the result remains negative.

As for diabetes group, (1) At COX-1(rs1330344), compared to the GG genotype, the GA genotype carriers had a lower susceptibility of diabetes, and this difference remained significant in multivariate analysis by adjusting for age, gender and traditional risk factors $(O R=0.711,95 \% C I=0.507-$ 0.996, $P=0.047$ ), and compared to the $G$ allele carriers genotype (GG + GA), the AA genotype carriers had a higher susceptibility of diabetes, and this difference remained significant in multivariate analysis by adjusting for age, gender and traditional risk factors $(O R=1.319,95 \% C I=1.036-$
1.680, $P=0.025)$.(2)At COX-2(rs20417), compared to the GG genotype, the GC genotype carriers had a lower susceptibility of diabetes, and this difference remained significant in multivariate analysis by adjusting for age, gender and traditional risk factors $(O R=0.616,95 \% C I=0.391-0.969$, $P=0.036$ ).(3) At COX-2(rs689466), compared to the GG genotype, the AA genotype carriers had a lower susceptibility of diabetes, and this difference remained significant in multivariate analysis by adjusting for age, gender and traditional risk factors $(O R=0.700,95 \% C I=0.502-0.977, P=$ 0.036).

As for smoking group, (1) At COX-1(rs5788), compared to the $\mathrm{CC}$ genotype, the A allele carriers genotype $(\mathrm{CA}+\mathrm{AA})$ carriers had a difference between smoking group and control group, this difference remained 


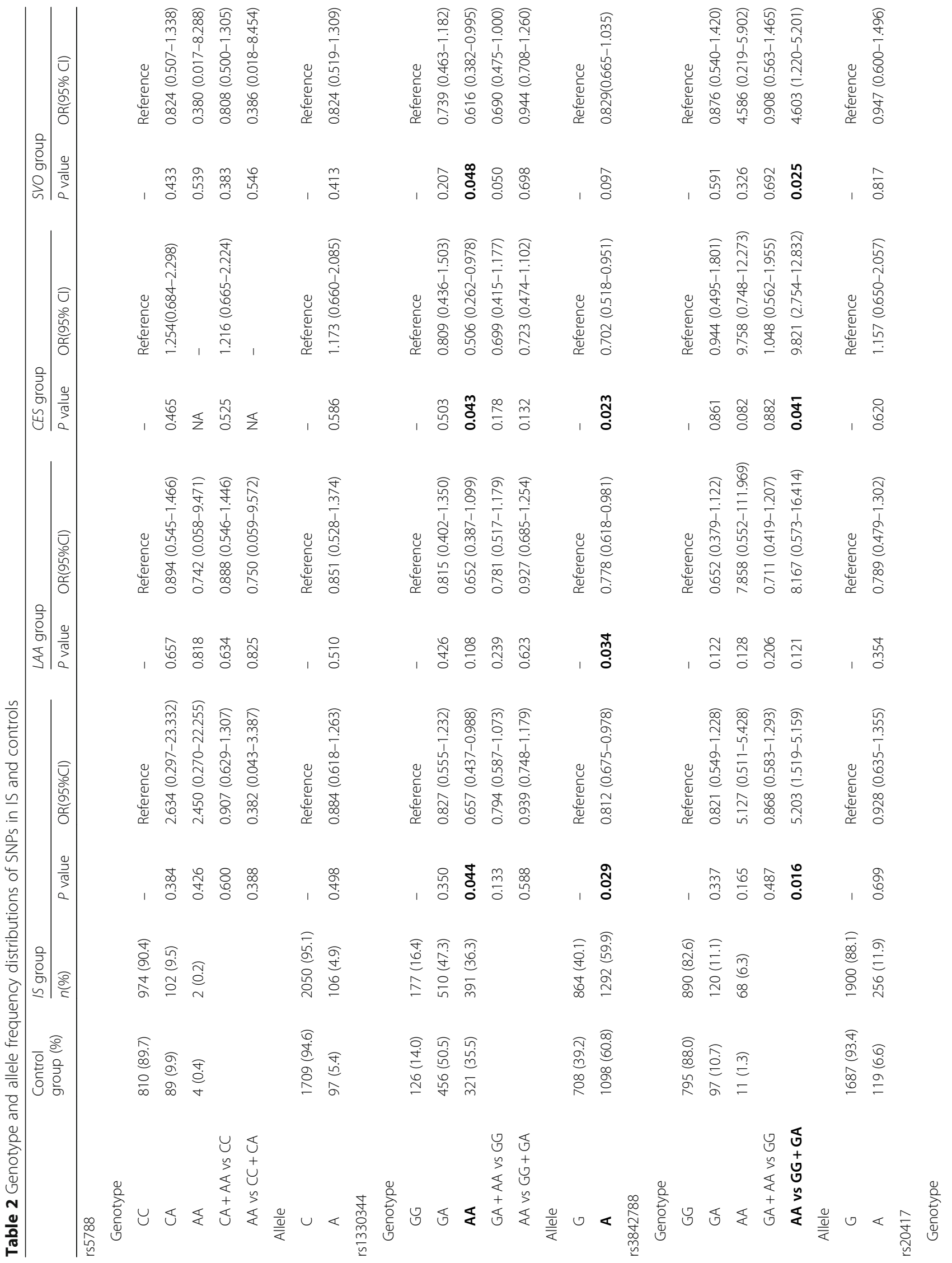




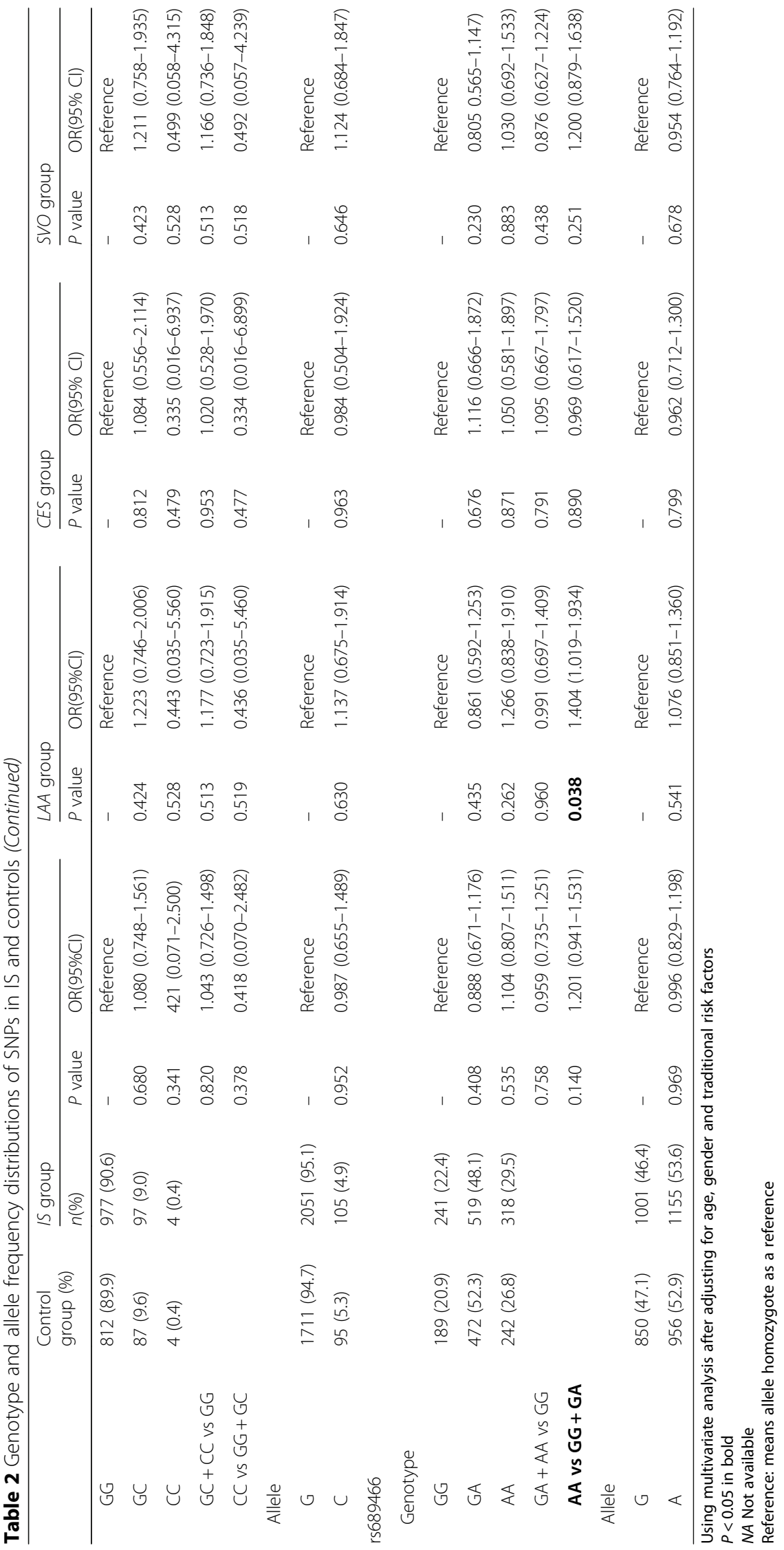




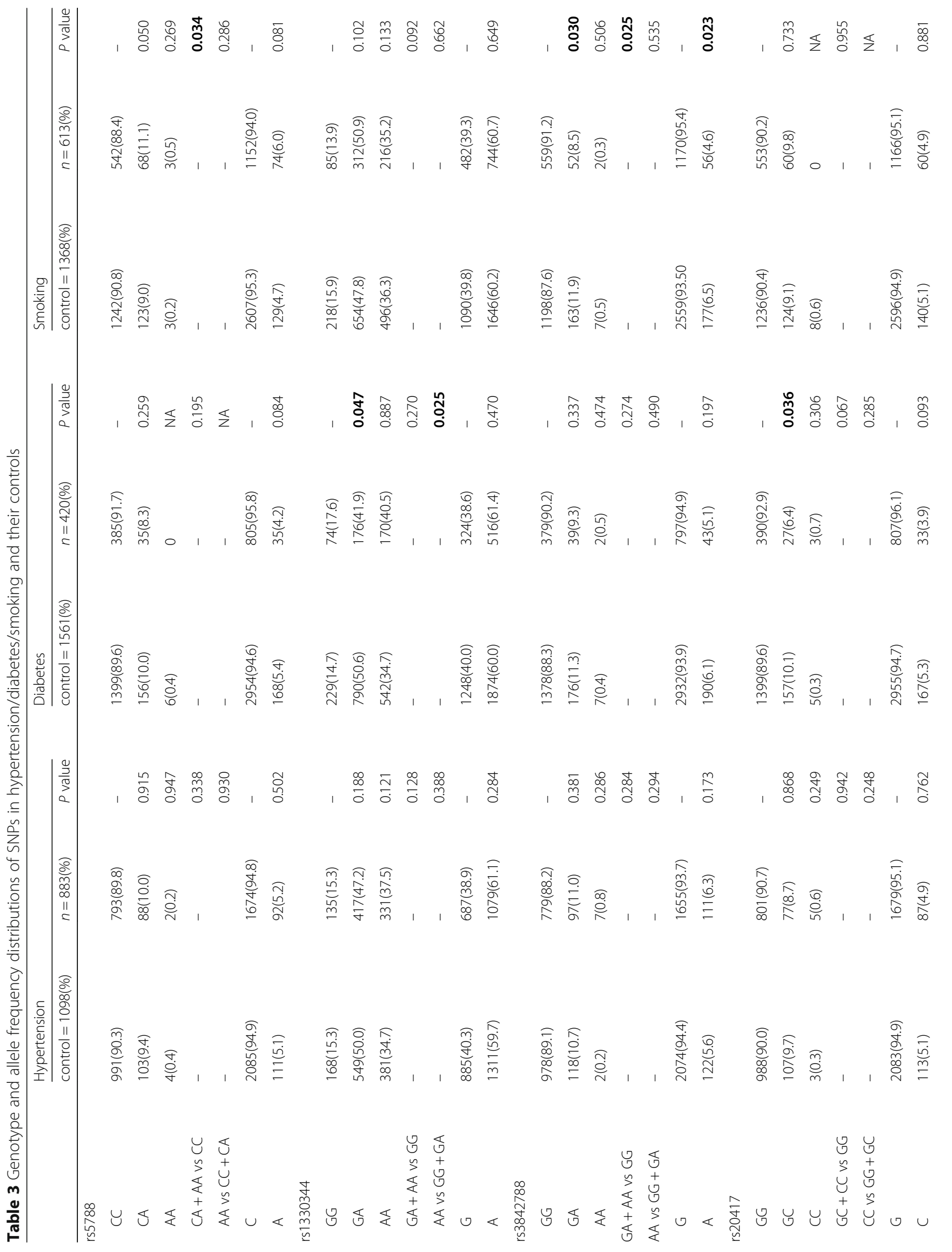




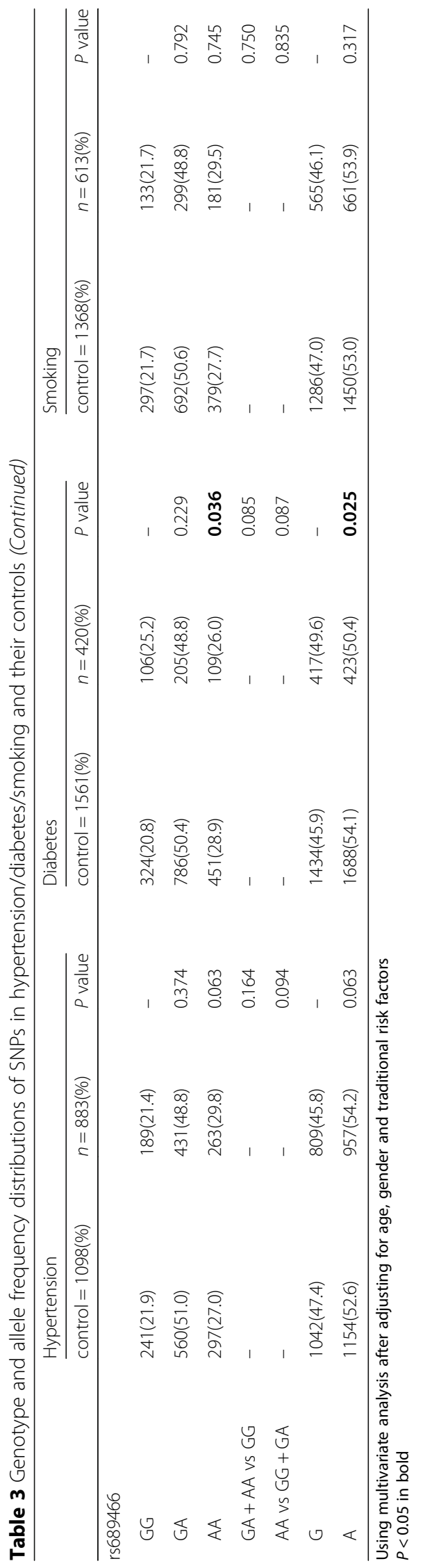


significant in multivariate analysis by adjusting for age, gender and traditional risk factors $(O R=1.525,95 \% C I=$ 1.031-2.255, $P=0.034)$. (2) At COX-2(rs3842788), compared to the GG genotype, the GA genotype and the A allele carriers genotype $(\mathrm{GG}+\mathrm{GA})$ had a significant difference between smoking group and control group, and this difference remained significant in multivariate analysis by adjusting for age, gender and traditional risk factors $(O R=0.631,95 \% C I=0.416-0.957, P=0.030 . O R=$ $0.626,95 \% C I=0.415-0.943, P=0.025)$.

\section{MDR analysis}

Gene-gene interactions were investigated for ischemic stroke and its subtypes by using MDR, and two models of SVO were statistical significant (Permutation test $P$ value $<0.05$, Table 4). Among all gene-gene interaction models evaluated, a two-locus model (rs1330344 and rs689466) with the maximum cross-validation consistency (CVC: $10 / 10)$ and testing accuracy (0.5304) was regarded as the overall best model in our study. In addition, the best three-locus model (including rs1330344, rs3842788 and rs689466) had a maximum CVC (10) and higher testing accuracy (0.5125).

\section{Additive effect analysis}

We used multiple logistic regression analysis to analyze the correlation between the additive effect of COX-1 (rs1330344, rs3842788), COX-2 (rs689466) and ischemic stroke. Setting: the risk allele for each locus was 1 , and the remainder was 0 . We compared the carrying $1,2,3$ risk loci to carry 0 risk loci without taking into account the specific loci or genes, just carrying any polymorphic loci count. Compared with those carrying none of the variants, individuals carrying one variant, carrying two variants and carrying three variants had no significant differences of the risk of ischemic stroke or its subtypes. (Table 5).

\section{Discussion}

COX gene is closely related to the cause of ischemic stroke. COX-1 gene locates on chromosomes 9q32-q33.3, contains 11 exons and 10introns [31]. COX-1 participates in the normal physiological metabolism of the body and regulates platelet function and blood coagulation [9]. When the vascular endothelial is harmed, it will cause the platelet adhesion, aggregation and activation, leading to platelet consumption. At the same time, the blood system will be activated to megakaryocyte, produce more dense granules, high enzyme activity, active function, and increase aggregation and adhesion ability of large volume platelet, further leading to thrombosis [32]. At present, multiple gene polymorphism loci has been found that in the COX-1 gene coding and non-coding area.

As for COX-1, our results showed that rs1330344 and rs3842788 contributed significantly to the occur of ischemic stroke, but the genotype and allele frequencies at rs5788 had no significant difference between ischemic stroke group and the control group. On one hand, at rs1330344, AA genotype may reduce the susceptibility of ischemic stroke, and CES or SVO. Meanwhile, the A allele carriers also may reduce the susceptibility of ischemic stroke, LAA or CES. On the other hand, at rs3842788, the

Table 4 MDR models of gene-gene interactions between three SNPS

\begin{tabular}{|c|c|c|c|c|c|c|c|c|c|c|}
\hline \multirow[t]{2}{*}{$\overline{S N P}$} & \multicolumn{5}{|l|}{15} & \multicolumn{5}{|l|}{$\angle A A$} \\
\hline & $\begin{array}{l}\text { Best candidate } \\
\text { model }\end{array}$ & $\begin{array}{l}\text { Training } \\
\text { accuracy }\end{array}$ & $\begin{array}{l}\text { Testing } \\
\text { accuracy }\end{array}$ & CVC & $\begin{array}{l}\text { Permutation test } \\
P \text { value }\end{array}$ & $\begin{array}{l}\text { Best candidate } \\
\text { model }\end{array}$ & $\begin{array}{l}\text { Training } \\
\text { accuracy }\end{array}$ & $\begin{array}{l}\text { Testing } \\
\text { accuracy }\end{array}$ & CVC & $\begin{array}{l}\text { Permutation test } \\
P \text { value }\end{array}$ \\
\hline 1 & SNP3 & 0.5216 & 0.4981 & $\begin{array}{l}7 \\
/ 10\end{array}$ & 0.206 & SNP3 & 0.5342 & 0.5342 & $\begin{array}{l}10 / \\
10\end{array}$ & 0.4270 \\
\hline 2 & $\begin{array}{l}\text { SNP1 } \\
\text { SNP3 }\end{array}$ & 0.5375 & 0.5211 & $\begin{array}{l}10 \\
/ 10\end{array}$ & 0.300 & $\begin{array}{l}\text { SNP1 } \\
\text { SNP3 }\end{array}$ & 0.5504 & 0.5346 & $\begin{array}{l}10 / \\
10\end{array}$ & 0.8400 \\
\hline 3 & $\begin{array}{l}\text { SNP1 } \\
\text { SNP2 } \\
\text { SNP3 }\end{array}$ & 0.5445 & 0.5176 & $\begin{array}{l}10 \\
110\end{array}$ & 0.330 & $\begin{array}{l}\text { SNP1 } \\
\text { SNP2 } \\
\text { SNP3 }\end{array}$ & 0.5591 & 0.5185 & $\begin{array}{l}10 / \\
10\end{array}$ & 0.5600 \\
\hline \multirow[t]{2}{*}{ SNP } & CES & & & & & SVO & & & & \\
\hline & $\begin{array}{l}\text { Best candidate } \\
\text { model }\end{array}$ & $\begin{array}{l}\text { Training } \\
\text { accuracy }\end{array}$ & $\begin{array}{l}\text { Testing } \\
\text { accuracy }\end{array}$ & CVC & $\begin{array}{l}\text { Permutation test } \\
P \text { value }\end{array}$ & $\begin{array}{l}\text { Best candidate } \\
\text { model }\end{array}$ & $\begin{array}{l}\text { Training } \\
\text { accuracy }\end{array}$ & $\begin{array}{l}\text { Testing } \\
\text { accuracy }\end{array}$ & CVC & $\begin{array}{l}\text { Permutation test } \\
P \text { value }\end{array}$ \\
\hline 1 & SNP1 & 0.5228 & 0.4834 & $5 / 10$ & $0.7600-0.7610$ & SNP1 & 0.53 & 0.53 & $\begin{array}{l}10 \\
/ 10\end{array}$ & 0.8520 \\
\hline 2 & $\begin{array}{l}\text { SNP1 } \\
\text { SNP3 }\end{array}$ & 0.5383 & 0.4776 & $\begin{array}{l}10 / \\
10\end{array}$ & 0.9510 & $\begin{array}{l}\text { SNP1 } \\
\text { SNP3 }\end{array}$ & 0.5428 & 0.5304 & $\begin{array}{l}10 \\
/ 10\end{array}$ & $0.0050-0.0060$ \\
\hline 3 & $\begin{array}{l}\text { SNP1 } \\
\text { SNP2 SNP3 }\end{array}$ & 0.5552 & 0.4592 & $\begin{array}{l}10 / \\
10\end{array}$ & $0.7990-0.8000$ & $\begin{array}{l}\text { SNP1 } \\
\text { SNP2 SNP3 }\end{array}$ & 0.5496 & 0.5125 & $\begin{array}{l}10 \\
/ 10\end{array}$ & $0.0190-0.0200$ \\
\hline
\end{tabular}

$P<0.05$ in bold

COX-1 rs1330344, rs3842788, COX-2 rs689466 signed as SNP1-3

CVC(cross-validation consistency) 
Table 5 Additive effect analysis between three SNPS

\begin{tabular}{|c|c|c|c|c|c|c|c|}
\hline \multirow[t]{2}{*}{ Risk loci } & \multirow[t]{2}{*}{ control(\%) } & \multicolumn{3}{|l|}{ is } & \multicolumn{3}{|l|}{$\angle A A$} \\
\hline & & $n(\%)$ & $\mathrm{OR}(95 \% \mathrm{Cl})$ & $P$ value & $n(\%)$ & $\mathrm{OR}(95 \% \mathrm{Cl})$ & $P$ value \\
\hline 0 & $22(2.4)$ & $32(3.0)$ & Reference & & $13(3.2)$ & Reference & \\
\hline 1 & $230(25.5)$ & $294(27.3)$ & $0.856(0.341-2.151)$ & 0.741 & $105(25.9)$ & $0.646(0.215-1.942)$ & 0.437 \\
\hline 2 & $586(64.9)$ & $694(64.4)$ & $0.752(0.323-1.752)$ & 0.509 & $270(66.7)$ & $0.587(0.216-1.595)$ & 0.296 \\
\hline 3 & $65(7.2)$ & $58(5.4)$ & $0.400(0.144-1.111)$ & 0.079 & $17(4.2)$ & $0.231(0.056-0.951)$ & 0.052 \\
\hline \multirow[t]{2}{*}{ Risk loci } & control(\%) & CES & & & SVO & & \\
\hline & & $n(\%)$ & $\mathrm{OR}(95 \% \mathrm{Cl})$ & $P$ value & $n(\%)$ & $\mathrm{OR}(95 \% \mathrm{Cl})$ & $P$ value \\
\hline 0 & $22(2.4)$ & $4(2.9)$ & Reference & & $15(2.8)$ & Reference & \\
\hline 1 & $230(25.5)$ & $33(24.3)$ & $0.881(0.231-3.645)$ & 0.861 & 156(29.1) & $1.178(0.388-3.576)$ & 0.773 \\
\hline 2 & $586(64.9)$ & $88(64.7)$ & $0.677(0.183-2.502)$ & 0.558 & $336(62.6)$ & $0.747(0.272-2.050)$ & 0.572 \\
\hline 3 & $65(7.2)$ & $11(8.1)$ & $0.220(0.023-2.147)$ & 0.193 & $30(5.6)$ & $0.493(0.148-1.644)$ & 0.250 \\
\hline
\end{tabular}

Using multivariate analysis after adjusting for age, gender and traditional risk factors

susceptibility of ischemic stroke was fivefold higher in the AA genotype than in the $\mathrm{G}$ allele carrier genotype (GG + $\mathrm{GA}$, recessive model); the susceptibility of CES was higher by about 9.8 times; the risk of SVO was higher by about 4.6 times. Our finding matches a study of 859 ischemic stroke patients indicated the rs5788 locus is not related to ischemic stroke in China [23]. But they also suggested that the homozygotes of the minor allele at rs1330344 increase the risk of ischemic stroke recurrence, which was inconsistent with our findings. This difference may be caused we included different type of ischemic stroke patients. Their study included patients with recurrent ischemic stroke, and all of the patients were classified as one type. Instead, our study included first onset of ischemic stroke patients and grouped them by the TOAST classification. In addition, another study of 196 ischemic stroke patients in Korea revealed that the rs 3842788 locus is not associated with ischemic stroke, and a study of 469 ischemic stroke patients in USA also got the same results, both of which were inconsistent with our results [24]. This may because these studies all had relatively small samples and involving different ethnic population.

COX-2 gene located on chromosomes 1q25.2-q25.3, contains 10 exons and 9 introns, mainly in the nuclear membrane of cells, so the PGs products can enter the nucleus, which regulates target gene transcription [31]. COX-2 is induced enzyme, exists in vascular endothelial cells, smooth muscle cells and platelets.COX-2 is one of the key enzymes involved in AA generation to PG. [22] It will only highly expressed when the cells affected by various factors participates in physiological and pathological processes of inflammation or tumor [18]. COX-2 expression is 10-20 times higher in patients with atherosclerotic plaques or inflammatory stimuli than in asymptomatic patients with arterial stenosis [33]. Rs20417 and rs689466 are located in the promoter position at COX-2 gene, to participate in regulating gene transcription and specificity, previous studies showed that these loci mutation can change the promoter activity which will affect the expression of COX-2.

As for COX-2, our results showed that the genotype and allele frequencies at rs 20417 had no significant difference between the ischemic stroke group and the control group. This conclusion is consistent with a meta-analysis of rs20417 [25] and two studies (411 ischemic stroke patients in China, 469 ischemic patients in USA) [34, 35]. However, there were some controversial researches of rs20417. Francesco et al. [22] observed that the GC and CC genotypes of rs20417 are related to the pathogenesis of ischemic stroke, and $\mathrm{C}$ allele may be a genetic protective factor that reduces the incidence of ischemic stroke. Conversely, a study showed that the GC and CC genotypes were commonly found in African-American and European populations affected by ischemic stroke and suggested that COX-2 is an ischemic stroke-susceptible gene [20]. In our study, the difference between ischemic stroke group and control group at rs20417 was not significant, this may due to the difference between our population and genetic heterogeneity. Furthermore, at COX-2(rs689466), we found the AA genotype carriers had a higher risk of LAA, compared to the G allele carriers genotype $(G G+G A)$. Our finding proved that rs689466 was associated with susceptibility to ischemic stroke in China which matched the results of a Chinese population study (Zhejiang Province-224 patients with LAA and 329 patients with SVO [26]). But the effect of the study was confined to SVO among the stroke subtypes rather than to LAA which was dissimilar to our study. This may be caused by their small amounts of patients. Therefore, it is very important that more large samples and multiethnic studies need to be conducted to verify the association of rs689466 with ischemia stroke in China.

There were some differences observed in genotype and allele frequencies between the diabetes/smoking group 
and control group, and this difference remained significant in multivariate analysis after adjusting for age, gender and traditional risk factors. Inflammation may play a role in the pathogenesis of type 2 diabetes, COX generates prostaglandins, which negatively modulate glucosestimulated insulin secretion. This indicated that COX may associate with diabetes [36]. Konheim et al. identified that there was no association of COX2 rs689466 with type 2 diabetes [37]. Their conclusion matched another hospital-based case-control study in Turkey [38]. However, our study found that COX-1 rs1330344 and COX-2 (rs20417, rs689466) were associated with diabetes. The racial difference may cause this inconsistent. Since smoking increases the activity of inflammatory mediators through an increase in leukotriene synthesis essential in atherosclerosis pathogenesis, COX functions as a mediator of the inflammatory response and is also essential in atherosclerosis pathogenesis [39]. Our study found that COX-1 rs5788 and COX-2 rs3842788were associated with smoking, this evidence may explain that the pathogenesis of COX associate with smoking.

We had got some statistically significant positive results from the single gene polymorphism research of COX-1 and COX-2 gene. But these results were not entirely consistent with existing research and cannot fully explain the association between each polymorphism in the same gene. Therefore, we conducted a study on the interaction between multiple loci in ischemic stroke. Our study found that COX-1(rs1330344, rs3842788) and COX-2 rs689466 are associated with SVO. Compared with those patients who do not carry any of the variants, individuals carrying one variant, two variants, and three variants had no significant difference between the ischemic stroke and the control groups. Our previous results showed that rs1330344 reduces the risk of ischemic stroke, including CES and SVO, whereas rs3842788 increases the risk of ischemic stroke, including CES and SVO, rs689466 increases the risk of LAA, and the three loci interact with SVO. Our study also had several limitations. First of all, our study only included the Han population in the southwest of China. Secondly, our study only examined two and three loci of the candidate genes and thus may be unable to cover the entire gene linkage disequilibrium signal. Hence, a linkage disequilibrium map of the gene should be constructed to clarify the relationship between this gene and the pathogenesis of ischemic stroke. Thirdly, this study was limited to two genes and three loci to explore the gene-gene interaction in ischemic stroke. The quantification of the environmental factors of ischemic stroke was relatively difficult. Thus, the role of the interaction of environmental factors was not considered in our study. Therefore, future studies on gene interaction should include environmental and epigenetic factors and should also be performed to enhance our understanding of the genetic structure of ischemic stroke, to investigate the molecular mechanism of ischemic stroke, and to provide a new angle for the diagnosis and treatment of ischemic stroke.

\section{Conclusion}

At rs1330344, AA genotype may reduce the susceptibility of ischemic stroke. At rs3842788, AA genotype may increase the susceptibility of ischemic stroke. At rs689466, AA genotype may increase the susceptibility of large-artery atherosclerosis (LAA). COX-1(rs1330344, rs3842788) and COX-2 rs689466 interacted in small vessel occlusion (SVO), but had no additive effect with ischemic stroke or its subtypes in a Han population from Southwest China.

\section{Abbreviations \\ CES: Cardioembolic stroke; COX gene: Cyclooxygenase gene; LAA: Large- artery atherosclerosis; SVO: Small vessel occlusion}

\section{Acknowledgements}

Not applicable.

\section{Authors' contributions}

$L Z, M Z, L Y, N C$ and $L H$ were responsible for the concept and design of the study. LZ, JF and JZ were responsible for collecting and analyzing the data. LZ was responsible for drafting the manuscript. JF was responsible for the study coordination and interpretation of data. All authors participated in review and revision of the manuscript. All authors read and approval the final manuscript.

\section{Funding}

No funding was received from any organization or individuals.

\section{Availability of data and materials}

The database used and/or analyzed during the current study are available from the corresponding author on reasonable request.

\section{Ethics approval and consent to participate}

Our clinical research was reviewed and approved by the Ethics Review Committee of West China hospital, Sichuan University. We obtained patients' written consents for their clinical information and blood samples. We would get their verbal consents when we obtained their blood samples for SNPs tests.

\section{Consent for publication}

No applicable.

\section{Competing interests \\ The authors declare that they have no competing interests.}

Received: 8 December 2018 Accepted: 21 October 2019

Published online: 17 November 2019

\footnotetext{
References

1. Roger VL. Heart disease and stroke statistics--2011 update: a report from the American Heart Association. Circulation. 2011;123(4):e18-e209.

2. Yang G, et al. Rapid health transition in China, 1990-2010: findings from the global burden of disease study 2010. Lancet. 2013;9882(9882):1987-2015.

3. Matarin $M$, et al. The genetics of ischaemic stroke. J Intern Med. 2010; 267(2):139-55.

4. Rothwell PM, et al. Change in stroke incidence, mortality, case-fatality, severity, and risk factors in Oxfordshire, UK from 1981 to 2004 (Oxford vascular study). Lancet. 2004;363(9425):1925-33.

5. Rubattu S, Giliberti R, Volpe M. Etiology and pathophysiology of stroke as a complex trait $\vec{i}$. Am J Hypertens. 2000;13(10):1139-48.
} 
6. Rosengren A, et al. Association of psychosocial risk factors with risk of acute myocardial infarction in 11119 cases and 13648 controls from 52 countries (the INTERHEART study) : case-control study. Lancet. 2004;364(9438):953-62.

7. Emsley HCA, et al. An early and sustained peripheral inflammatory response in acute ischaemic stroke: relationships with infection and atherosclerosis. J Neuroimmunol. 2003;139(1-2):93-101.

8. Funk CD. Prostaglandins and leukotrienes: advances in eicosanoid biology. Science. 2001;294(5548):1871-5.

9. Calder PC. Polyunsaturated fatty acids and inflammatory processes: new twists in an old tale. Biochimie. 2009;91(6):791-5.

10. Solveig $\mathrm{G}$, et al. The gene encoding phosphodiesterase $4 \mathrm{D}$ confers risk of ischemic stroke. Nat Genet. 2003;35(2):131-8.

11. Jesper M, Marcel K. Functional SNP in an Sp1-binding site of AGTRL1 gene is associated with susceptibility to brain infarction. Hum Mol Genet. 2007; 16(6):630-9.

12. Ikram MA, et al. Genomewide association studies of stroke. N Engl J Med. 2009:360(17):1718-28.

13. $\mathrm{Xu} C \mathrm{Q}$, et al. Minor allele $\mathrm{C}$ of chromosome $1 \mathrm{p} 32$ single nucleotide polymorphism rs11206510 confers risk of ischemic stroke in the Chinese Han population. Stroke. 2010;41(8):1587-92.

14. Tomonaga $M$, et al. Functional SNP of ARHGEF10 confers risk of atherothrombotic stroke. Hum Mol Genet. 2010;19(6):1137-46.

15. Helgadottir, A., ., et al., Association between the gene encoding 5lipoxygenase-activating protein and stroke replicated in a Scottish population. Am J Hum Genet, 2005. 76(3): p. 505-509.

16. Warner TD, Mitchell JA. Cyclooxygenases: new forms, new inhibitors, and lessons from the clinic. FASEB J. 2004;18(7):790-804.

17. Cipollone, F., ., et al., Overexpression of functionally coupled cyclooxygenase-2 and prostaglandin E synthase in symptomatic atherosclerotic plaques as a basis of prostaglandin E(2)-dependent plaque instability. Circulation, 2001. 104(8): p. 921-927.

18. Vane J, Bakhle Y, Botting RM. Cyclooxygenases 1 and 2. Annu Rev Pharmacol Toxicol. 1998;38(1):97-120.

19. Maree $\mathrm{AO}$, et al. Cyclooxygenase-1 haplotype modulates platelet response to aspirin. J Thromb Haemost. 2005;3(10):2340-5.

20. Kohsaka $\mathrm{S}$, et al. Increased risk of incident stroke associated with the cyclooxygenase 2 (COX-2) G-765C polymorphism in African-Americans: the atherosclerosis risk in communities study. Atherosclerosis. 2008;196(2):926-30,

21. Donatella $\mathrm{C}$, et al. The COX-2 G/C -765 polymorphism may modulate the occurrence of cerebrovascular ischemia. Blood Coagul Fibrinolysis. 2006;17(2):93-6

22. Francesco $\mathrm{C}$, et al. A polymorphism in the cyclooxygenase 2 gene as an inherited protective factor against myocardial infarction and stroke. JAMA. 2004;291(18):2221-8.

23. Cao $L$, et al. Impacts of COX-1 gene polymorphisms on vascular outcomes in patients with ischemic stroke and treated with aspirin. Gene. 2014;546(2):172-6.

24. Kim DH, et al. A promoter polymorphism (rs17222919, -1316T/G) of ALOX5AP is associated with intracerebral hemorrhage in Korean population. Prostaglandins Leukot Essent Fat Acids. 2011;85(3-4):115-20.

25. Li W, et al. Cyclooxygenase-2 (COX-2) G-765C is a protective factor for coronary artery disease but not for ischemic stroke: a meta-analysis. Atherosclerosis. 2009;207(2):492-5.

26. Chen GZ, et al. Cyclooxygenase-2 genetic polymorphism and stroke subtypes in Chinese. J Mol Neurosci. 2013;51(2):467-73.

27. Stroke--1989. Recommendations on stroke prevention, diagnosis, and therapy. Report of the WHO Task Force on Stroke and other Cerebrovascular Disorders. Stroke. 1989;20(10):1407-31.

28. Adams HP, et al. Classification of subtype of acute ischemic stroke. Definitions for use in a multicenter clinical trial. TOAST. Trial of org 10172 in acute stroke treatment. Stroke. 1993;24(1):35-41.

29. Hallstrom AP, Cobb LA, Ray R. Smoking as a risk factor for recurrence of sudden cardiac arrest. N Engl J Med. 1986;314(5):271-5.

30. Langaee T, Ronaghi M. Genetic variation analyses by pyrosequencing. Mutat Res. 2005:573(1-2):96-102.

31. Tetsuya K, et al. Characterization of the human gene (PTGS2) encoding prostaglandin-endoperoxide synthase 2. Eur J Biochem. 1994;221(3):889-97.

32. Avinoam S, Alex S. Tricuspid regurgitation in mitral valve disease incidence, prognostic implications, mechanism, and management. J Am Coll Cardiol. 2009;53(5):401-8.

33. Vucević $D$, et al. Inflammatory process in atherogenesis: new facts about old flame. Med Pregl. 2012;65(9-10):388-95.
34. Yi XY, et al. Interaction between ALOX5AP-SG13S114A/T and COX-2-765G/C increases susceptibility to cerebral infarction in a Chinese population. Genet Mol Res. 2013;12(2):1660-9.

35. Lemaitre RN, et al. Variation in eicosanoid genes, non-fatal myocardial infarction and ischemic stroke. Atherosclerosis. 2009;204(2):e58-63.

36. $A D P$, et al. C-reactive protein, interleukin 6 , and risk of developing type 2 diabetes mellitus. JAMA. 2001;286(3):327-34.

37. YL K, JK W. Association of a promoter variant in the inducible cyclooxygenase-2 gene (PTGS2) with type 2 diabetes mellitus in Pima Indians. Hum Genet. 2003;113(5):377-81.

38. Ozbayer $\mathrm{C}$, et al. Genetic variant in the $3^{\prime}$-untranslated region of the COX2 gene is associated with type 2 diabetes: a hospital-based case-control study. Prostaglandins Leukot Essent Fat Acids. 2018;137:39-42.

39. Merhi $\mathrm{M}$, et al. Impact of inflammation, gene variants, and cigarette smoking on coronary artery disease risk. Inflamm Res. 2015;64(6):415-22

\section{Publisher's Note}

Springer Nature remains neutral with regard to jurisdictional claims in published maps and institutional affiliations.
Ready to submit your research? Choose BMC and benefit from:

- fast, convenient online submission

- thorough peer review by experienced researchers in your field

- rapid publication on acceptance

- support for research data, including large and complex data types

- gold Open Access which fosters wider collaboration and increased citations

- maximum visibility for your research: over $100 \mathrm{M}$ website views per year

At BMC, research is always in progress.

Learn more biomedcentral.com/submissions 